\title{
A RESEARCH BASIS FOR CORRECTIVE ACTION WITH RESPECT TO INTERTERRITORIAL FREIGHT RATES
}

\author{
James C. Nelson*
}

If the controversy over the effects of interterritorial freight-rate discrimination had stimulated as much effort to assemble needed data and to trace concretely the specific effects of rate disparities applicable to particular market situations as it has argumentative effort, it would be far easier to design and obtain corrective action. As indicated in another article in this symposium, ${ }^{1}$ there is evidence, both factual and logical, that existing interterritorial rate disparities have a burdensome effect upon individual firms having to pay the higher rates, distance considered, and through them upon whole rate territories. Nevertheless, although some noteworthy beginnings have been made toward providing an adequate factual basis for judgment, it is clear that rate and other data necessary to examination of crucial questions, such as the extent of disparities in commodity rates and their effects, are not at hand. ${ }^{2}$ It is the purpose of this note to outline some areas of statistics where additional progress is needed and to indicate some essential types of analyses that are lacking.

\section{I}

\section{Nature of the Problem}

Freight-rate discrimination has become a popular subject for discussion during the past two decades because of its allegedly retarding effect upon the location of industry, the development of industrial resources, and the utilization of labor power in several rate territories of the United States, particularly in the southern and south-

* A.B. 1930, University of Washington; M.A. I93 , Ohio State University; Research Fellow Brookings Institution, 1933-34; Ph.D. 1934, University of Virginia. Chief, Transportation Division, Office of Domestic Commerce, U. S. Department of Commerce. Formerly Assistant Director, Division of Economic Studies, Board of Investigation and Research; Principal Economist, National Resources Planning Board; Senior Transportation Economist, Bureau of Agricultural Economics; Associate Professor of Marketing and Transportation, University of Tennessee; Acting Professor of Economics, University of Richmond; Acting Assistant Professor of Economics, University of Virginia; and Chief, Division of Research and Statistics, Washington Department of Public Service. Author of Federal Regulatonx Restrictions upon Motor and Water Carriers, Sen. Doc. No. 78, 79th Cong., ist Scss. (1945); New Concepts in Transport Regulations, Transportation and National Policy, National Resources Planning Board, pp. 197-237 (I942). Contributor to economic journals.

This article represents the views of the author and not necessarily those of the United States Department of Commerce.

${ }^{2}$ See Barton, Economic Effects of Discriminatory Rates, supra.

${ }^{2}$ Thus, in its report on the Class Rate Investigation, 1939, the Interstate Commerce Commission stated (262 I.C.C. 447,593 (1945)): "In many instances, commodity rates in the South are lower than commodity rates on like traffic in official territory. There is no comprehensive showing as to the general level of commodity rates in the South as compared with that in official territory." 
western territories. The economic problem, then, is to define the specific influences that varying territorial rate levels may exert upon these factors and to find the magnitudes of those effects. The regulatory problem, on the other hand, is somewhat different, for whether or not the retarding and burdensome effects upon some industries or locations are of relatively large magnitude, any unjustifiable rate discrimination under the Interstate Commerce Act should be removed.

The types of effects that varying freight-rate levels may have upon producers, distributors, and other elements of the population located in different territories can be determined on the basis of assumption and logical analysis. For example, if we assume that producer $A$, located in official territory, and producer $B$, located in southern territory, have identical production and marketing costs for an identical product, but that in competing for sales in Chicago producer $A$ enjoys a lower rate than producer $B$ although they are equidistant from that market, it inescapably follows that producer $B$ will have to absorb a part of the higher freight rate by accepting a lower profit margin. While absorption of freight-rate differentials would not necessarily mean that the producers assessed higher rates would be seriously handicapped (because of the possibility that they may have offsetting lower costs in connection with other production or marketing factors or enjoy lower rates on their other products), the presence of offsetting factors of this type cannot be assumed to exist in all cases. A number of possibilities are clearly indicated for each market situation affected by freight-rate disparities, depending upon the comparative capital, labor, marketing, materials, and management costs of the competing producers operating with varying freight costs and upon the existence or nonexistence of market preferences justifying higher prices for the product of the firm having to pay higher freight.

It is evident that many assumptions are required even to work out deductively the types of effects that freight-rate disparities may have upon a particular manufacturing or distributing firm located in the higher-rated territory. The task of defining such effects upon the manufacturing system or upon the distribution structure of the higher-rated territory as a whole is infinitely more complex, for, except to the extent that all firms in a particular territory may be subject to the same cost and market factors, a large variety of assumptions would have to be made to cover the many different situations that would be found to exist. Even when sufficient cases to be representative of the over-all territorial interest had been considered, the far more important problem of measuring the magnitudes of the effects that freight-rate disparities may be having upon locational and production trends in a particular territory would remain for solution. Although essential as a first step in working out the types of effects that might be expected from unequal freight costs, deductive reasoning by itself is inadequate for the task of determining the over-all significance of territorial differences in freight rates.

The assessment of magnitudes of effect upon individual firms, industries, or rate territories from freight-rate disparities requires an inductive approach upon an abun- 
dance of facts covering a wide range of industrial situations and a large number of factors with respect to each industrial and marketing situation. In addition to the rate and mileage data essential to definition of the problem, specific facts would have to be assembled with respect to the following factors, among others:

I. The degree of homogeneity of the competing products produced in the different rate territories;

2. The extent to which market preferences for one or the other territory's product have been created by advertising or other marketing methods;

3. The extent to which the products of different territories are marketed in the same markets;

4. The prices received at wholesale in common markets for equivalent commodities produced by firms located in different rate territories;

5. The net receipts at the plant or mill in connection with sales of equivalent commodities produced in different territories but marketed in the same markets;

6. The costs sustained in producing equivalent products in different territories which are marketed in the same markets, including appraisal of the method of allocating joint and overhead costs;

7. The profit margins at the plant or mill in connection with production of equivalent products in different territories marketed in common markets.

Obviously, such intimate data are possessed, if at all, only by the competing firms located in the different territories, and their publication, if they were obtainable, would raise questions of disclosure of facts pertaining to individual business situations. ${ }^{3}$ Some fragmentary information of this sort appears in testimony and decisions in connection with rate cases dealing with complaints of discrimination, but it is difficult to assemble and is too incomplete for over-all analysis. For these reasons, examination of economic effects in terms of entire territories usually proceeds by reference to trends in population, income, value added by manufacturing, the value of industrial products, and the number of industrial jobs, rather than by delineation of the specific effects of rate disparities upon individual firms. Thus, comment is often not very selective, for comparative industrial trends in different territories reflect a variety of factors in addition to freight-rate differences. ${ }^{4}$ When coupled with analysis of the significance of each factor of production, such as the availability of key materials at low cost or of an economical labor supply, economic trend analysis may come closer to revealing the importance of freight rates. To make this approach really effective, however, case studies of individual industries are needed. Only in such studies can the freight-rate factor be analyzed thoroughly in con-

3 The OPA files of profit and loss statements and balance sheets collected for administration of price control during World War II might contain useful data. These statements exhibit detailed cost breakdowns for the period $5936-39$ and one or more wartime years. Unit costs and profits from manufacturing in a particular locality are included in some cases. It is uncertain at this stage, however, whether the data will be permanently filed, and if so, whether they could be made available for general use.

'Board of Investigation and Research, Report on Interterritorial Frejoit Rates, H. R. Doc. No. 303, 78th Cong., Ist Sess. 223 (I943). 
junction with the other locational factors exerting an influence upon the production and marketing situation of the higher-rated territories.

It is apparent that concrete discussion of economic effects from freight-rate disparities requires reference to all factors in the industrial situation, whether the analysis is focused upon the individual firm, an industry, or the entire industrial economy of a rate territory. Many series of data, in addition to transportation series, are therefore essential; but the greatest handicap experienced by those who attempt measurement of economic effects consists of the lack of adequate rate and traffic data for determining the extent of freight-rate differences by territorial, industrial, and commodity breakdowns, rather than the defects in our manufacturing and marketing series.

The lack of extensive rate and specific movement data may seem surprising in view of the well-known fact that freight tariffs and classifications must be filed with the regulatory body and be kept open to public inspection under the requirements of the Interstate Commerce Act. Notwithstanding this fact, one of the greatest barriers to constructive thinking and effective analysis of the economic significance of territorial freight-rate discrimination has been the lack of adequate specific rate, mileage, and traffic movement data to enable the parties to reach agreement upon the facts with respect to the extent of rate-level differences, the starting point for any examination of the subject on an over-all basis. Because of this deficiency in available data, it is extremely difficult to define the areas in the rate structure or the specific areas of traffic of an industry or territory which are affected by freight-rate differences sufficiently marked to have significance. The rate structure is so complex and facts about it are so hidden in technical tariffs and rate decisions that discussion and argument concerning economic effects frequently proceed without the benefit of prior definition of the precise commodity or mileage areas where freight-rate differences exist and of definite knowledge of the magnitude of rate differences or of the characteristics of the traffic movements affected by such rate differences as may exist. Under the circumstances, it is no wonder that public opinion is often confused and tends either to be unexcited or easily induced to accept stereotyped slogans of a political nature.

Since definition of the specific problems of discrimination that may be present in existing territorial rate structures is an obvious first step in analysis of the economic significance of freight-rate disparities, it is of interest to describe the particular types of transportation data which are needed for that purpose and to indicate the gaps that exist in the available data. Then, the means by which greater progress can be made toward supplying at least the most urgent data for settlement of current issues can be considered with profit.

\section{II}

\section{Transportation Data Needs and Gaps}

Among the most crucial of the relevant transportation series that are now generally unavailable are: (x) data showing for each territory and interterritorially the 
proportion of total carload and less-carload traffic that moves on class, exception, and commodity rates, including sub-classifications such as export, import, joint, and transit rates; (2) statistics showing point-to-point rate relationships on a representative sample basis for the entire railroad rate structure of the United States, intrastate, intraterritorially, and interterritorially; (3) data showing point-to-point shortline mileage relationships on a comparable sample basis; and (4) data showing on a comparable point-to-point sample basis the volume of traffic in each commodity that is transported on different types of rates and rate levels. It would be helpful to have similar data for other forms of transport, particularly truck and water transport, but the need is greatest for more adequate data on the rail rate structure and traffic pattern. These sets of transport data would not answer all questions, but at least they would have the merit of enabling the analyst to define in a specific manner the discriminatory situations which should receive attention.

\section{Traffic Movement by Types of Freight Rates}

Historically, the present interterritorial freight-rate discrimination problem arose primarily in connection with class rates. But because of the intimate relation between class rates and other types of rates, principally exception rates and commodity rates, and the fact that the bulk of the rail traffic moves upon the latter, the issues have inevitably spread to include exception and commodity rates as well. In fact, the issues of greatest economic significance to each rate territory and the country as a whole revolve around the commodity rates, on which the largest part of the traffic is transported. Obviously, therefore, knowledge concerning the proportion of traffic in each territory and between each set of rate territories that moves on each type of railroad rate is essential to straight thinking on effects of rate disparities.

As a result of a one-day waybill sample of 1942 carload traffic and other statistics available to the Interstate Commerce Commission, the proportions of carload railroad traffic that are carried on each general type of rate in each territory and between each set of territories are known with sufficient exactitude for assessing the over-all significance of territorial class-rate discrimination. ${ }^{5}$ However, since determination of economic effects of freight-rate differences requires analysis in terms of particular industries, particular commodities and products, particular markets and particular market conditions, it is also essential that data be available to reveal the proportions of the traffic of individual industries that are transported on class, exception, and commodity rates. Because no point-to-point tabulation of domestic railroad traffic as a whole has ever been completed on a sufficiently representative sample to indicate the types of rates on which the traffic in particular commodities is moved between each important set of origination and termination points in each freight-rate territory and as between rate territories, readily available data showing the types of rates which are important to particular industries and to particular commodities are not at hand. ${ }^{8}$

\footnotetext{
- Class Rate Investigation, I939, 262 I.C.C. 447, 479 (1945).

- The Bureau of Transport Economics and Statistics of the Interstate Commerce Commission has programmed a series of traffic-flow and rate-structure analyses based in part upon the 12-day waybill
} 
Thus, although it can be concluded that the considerable differences in territorial and interterritorial class-rate levels that are not justifiable by cost differences do not affect 85 per cent or more of the total railroad traffic, comprehensive analysis of the specific effects which these rate-level differences may have upon the particular industries which do make material use of class rates is blocked at the beginning by inadequate information. One must necessarily resort to illustrative case materials available in rate proceedings or undertake to assemble primary data from the industries affected by class-rate inequalities.

When the Class Rate Investigation decision ${ }^{7}$ was handed down by the Commission on May I5, I945, the writer received requests from several trade associations to prepare analyses of the special significance to the industries represented in those associations of the interim and long-run adjustments ordered by the Commission. In discussions with representatives of the associations and with commodity experts and industrial analysts it was quickly discovered that little or no information was available regarding the extent to which the traffic of the trade association membership moved on the class rates which were to be adjusted when the order of the Commission became effective. Nor was such data described in the Commission's report, although the summary of evidence by shippers on the effect of class-rate disparities for certain commodities provides fragmentary data on the commodity movements affected by class rates. ${ }^{8}$ Hence it was not feasible to prepare the type of analysis for these groups that would have been desirable. ${ }^{9}$ This lack of data on movement by types of rates, of course, did not prevent those groups and others from discussing the probable effects of the decision, but it did render much of that discussion futile and lent a quality of vagueness that should have been unnecessary.

\section{Point-to-Point Rate Relations}

Point-to-point rate data for all individual commodities of significance to our industrial and agricultural economies are needed to reveal the characteristics of the entire rail rate structure, the most fundamental one in terms of domestic freight traffic and geographic agricultural and industrial relationships. For each point-oforigin to each point-of-destination movement of an individual commodity, it would be desirable to have the first-class rate that would be applicable if no lower rate were quoted, the actual rate, and the characteristics of that rate-whether an exception or commodity rate, export or import rate, local, proportional, or joint rate, and whether

sample of 1939 carload traffic taken by the Board of Investigation and Research, of which The Transportation of Fresh Apples, Statement No. 468, File No. 40-C-2, March, 1946, is the first. Among the data on fresh apple traffic presented from this source is "the percentage of traffic moving under class, exception, and commodity rates, respectively." See pp. $47-48$ for a breakdown of revenues, tons, tonmiles, carloads, and car-miles by type of rate in each rate territory and pp. 64-68 for a similar breakdown of interterritorial movements of fresh apples.

262 I.C.C. 447 (1945).

${ }^{8}$ Id. at $6 \times 5-6 \mathrm{xg}$.

- The general analysis that resulted on the basis of available data was published under the title, Effect of New Rail Rates on Business, 33 Domestic Commerce, No. 8, 21-22, 44-45 (1945). 
the rate includes special services such as transit and reconsignment privileges. To be practical these data would have to be collected on a representative sample basis, but the sample would not have to be taken frequently, because adjustments could easily be made for general and special rate changes once the point-to-point rate pattern had been published.

Point-to-point rate statistics would shortly become as fundamental a tool for transportation factor analyses as population data have been for demographic studies. Such data would facilitate locating areas where rate differences may exist by states, territories, and combinations of territories. They would also greatly contribute to measurement of the extent of such rate disparities on individual commodities as may be found to exist between particular sets of points and to determination of differences in average rate levels for groups of commodities or territorial breakdowns. Except for a limited number of basic commodities moving on commodity rates, only data showing class-rate level differences have been available. Obviously, if freight-rate differences do not exist in connection with other types of rates, or those found to exist with respect to the rates on which the traffic actually moves are so insignificant as to be trifling, further study of probable economic effects, with extensive analysis of industrial trends, cost factors, and market relationships, would have little point. Of course, it may be presumed that since so much agitation has arisen there must be thousands, if not millions, of cases where freight-rate differences do exist. Many have been exposed in the course of rate proceedings and other investigations. Thus, measurement of these differences in connection with particular sets of origination and termination points or territorial rate levels would be an invaluable aid to making progress in ascertaining the economic significance of varying territorial and interterritorial rate levels. Since undue discrimination in freight rates is banned under the Interstate Commerce Act, the information on loads, actual and shortline mileages, extent of circuitous transportation, and other factors that might be collected at the same time would be useful in determining the specific costs of service as tests, among others, of the reasonableness of the rate differences found to exist.

Although point-to-point rate data would prove a material aid to constructive analysis of interterritorial freight-rate issues, it should be recognized that waybill sources for such statistics would show rate relations only with respect to traffic that actually has moved between specific points. Discriminations in rates that are so serious as to shut off the flow of traffic in particular commodities between points where production might occur and consuming markets would obviously not show up in data based on a sample of past traffic. Other sources, such as tariffs and classifications, would have to be relied upon for assembling the "paper" rates which have been so high as to discourage production and traffic flows completely.

It may be granted that small or minor differences in freight-rate levels as between particular sets of origination and destination points or territories may be disregarded as constituting insignificant barriers to industrial development and utilization of resources, and that it would not be a mark of economic wisdom to equalize all freight 
rates on a rigid distance-cost basis. On the other hand, freight-rate differences that are material cannot reasonably be passed over either by the regulatory body having the duty of eliminating discrimination not justified by differences in transportation conditions or by the analyst concerned with the economic significance of freight-rate disparities. With existing sources, however, there is no way, except by tedious and expensive examination of a great many tariffs and rate decisions, by which the analyst can discover whether differences in many freight rates may exist and whether they are sufficient to have significance. That procedure usually requires considerable technical knowledge and staff resources in order to dig the data for any large study from the tariffs and classifications. Sometimes scanning a great many rate decisions of the Commission in a search for rate chronologies and histories will be productive of useful data, although the series obtained in this manner will frequently be incomplete and not up to date. In addition, data found in rate proceedings refer generally only to particular commodity movements between specific sets of points rather than to the entire rate structure of a commodity or territory. Thus, as tools for describing freight-rate differences in the entire rate structure, these methods have deficiencies which defeat most attempts, even the most ambitious and persevering ones, to assemble the pertinent data.

One of the defects of most published comment on effects of territorial and interterritorial freight-rate disparities is that the freight-rate differences considered have been shown by reference to sets of points between which the traffic movements for which the rates have been compared are often noncompeting. That is to say, rates are selected for movements of the same commodity from different producing points to different markets. That device has been used because of the difficulty of obtaining adequate data for comparison of rates between alternative production locations and common markets where the shortline distances are comparable and also because the traffic pattern is not known with sufficient definiteness to make location of sets of points involving actual competition between movements easy. This method, of course, suffers from the serious defect of referring to market situations which may have little or no effect upon each other and to rate disparities that consequently cannot influence the opportunities and profits of the producers at different locations. Adequate point-to-point rate data, coupled with shortline mileages and traffic flow information, would greatly facilitate selection of sets of points involving common markets except in cases involving origin points from which no movement has occurred. In the latter situations, analysis would be benefited by having the sets of points between which movements do occur identified, together with the applicable rates and other essential information for comparative purposes.

\section{Point-to-point Mileage Relations}

In addition to the needs outlined above for point-to-point rate data, it is equally necessary that data be made available showing the point-to-point distances between the same sets of points for which specific rate information is needed. Of critical 
importance are the shortline distances-the mileages by the shortest practicable rail route between origination and termination points. The shortline distance is the "yardstick" mileage for comparing rates in terms of the transportation with which they are associated. Although shortline distance alone does not reflect all "transportation conditions" that must be considered by the regulatory body in judging whether rate differences involve unjust discrimination, it is a most significant measure of the transportation service rendered and is widely relied upon in rate proceedings.

The other distance measure, the actual number of miles over which the shipment moved, has its usefulness, too, particularly in studies of the extent and economic significance of circuitous mileage and cross-hauling. However, since neither shippers nor the railroads themselves are prohibited from selecting routes that are circuitous in order to control participation in the traffic, actual route miles cannot be utilized as a reliable "yardstick" in rate comparisons. The shortline distances between producing points $A$ and $B$ and the consuming point $C$ might be identical, but the shipment from $A$ over a circuitous route might be 20 per cent greater than if it had moved in the shortest route. Obviously, a rate from $A$ to $C 20$ per cent higher than from $B$ to $C$, between which the shipment had moved over the shortest practicable route, would not be justified although in accordance with the mileage relations determined by the actual routes used.

The problem of obtaining shortline distances by reference to tariffs, mileage books, and maps is even more baffling and time-consuming than the effort to obtain rate data from tariffs and classifications. To select the shortline route by these procedures usually requires a rate and tariff expert, for there appears to be available no directory publishing the shortest practicable rail routes for freight traffic between all sets of points and the distances associated with such routes. To work out the shortest route and distance may take a tariff expert up to a day or more in some of the more difficult instances. Although some shortline routes and distances between specific points can be found in the reported rate decisions of the Commission, that source itself has the limitations of being far from complete and involving considerable effort because the data in the decisions and transcripts are not indexed.

\section{Point-to-Point Traffic Movements}

Most available tonnage data providing commodity breakdowns refer to a limited number of commodity groups, each, with some exceptions, incorporating many individual commodities. Except for limited port-to-port water movement data, none of these series provides state-to-state or point-to-point breakdowns either of aggregate traffic or traffic in each commodity classification. Between 1922 and I940 data on intercoastal water traffic were published annually by the United States Maritime Commission and predecessor agencies on a port-to-port basis for a limited number of general commodity classifications. ${ }^{10}$ Beginning in 1940 the ICC's freight com-

${ }_{10}$ Research Division, U. S. Maritime Commission and predecessors, Ann. Reps. No. 317 (19221940). The Maritime Commission is resuming publication of this series, after a lapse during the war 
modity statistics for rail carriers have shown tonnages originated and terminated by states, but they have never shown state-to-state movements. ${ }^{11}$ For knowledge of the traffic significance of particular sets of points, the analyst must utilize a variety of statistical devices and refer to numerous sources, including reported rate decisions, traffic movement studies, and industrial studies having reference to production and consumption centers and traffic movements.

Where marked rate differences exist for comparable shortline mileages, it is of interest to know the volume of movement that has taken place despite these rate differences. If the volume has been considerable from the higher-rated point or territory and has registered growth, the question would arise whether the rate differentials had affected the higher-rated producers in any significant manner. Of course, as noted above, the producers may have elected to accept a lower profit margin or they may have had lower costs in connection with other factors in production or marketing. If, on the other hand, the movement from the point or territory with the higher rates had not grown as rapidly as the movement from the point or territory with the lower rates, the situation would point to a burdensome effect. In either case, if the rate disparities could not be justified by cost differences or other dissimilar transportation conditions, the higher-rated producers would be entitled to relief from unlawful discrimination irrespective of the effect of the rate differences upon the flow of traffic.

It is recognized that relative traffic movements between points would not throw light upon the effects of rate differences in cases where production might exist at a point but has never developed because freight rates on raw materials or finished products, or both, have been too high to make location there attractive. In such situations an effective freight rate from the points at which new plant locations are being considered to the contemplated markets would have to be established to replace the "paper" rates, presumably class rates, that are too high to serve as a practical basis for attracting industry. The rate and distance relations between the points from which movement does occur to the markets for the commodities under consideration, however, would reveal the extent to which existing class rates are impractical and would afford a basis for rate negotiations with a view to providing rates which would effectively stimulate industry. In other cases, some movement, but only a small volume, occurs from certain points where production has been established despite higher freight rates than those applicable from competing points. In these cases the problem is to determine what rate will stimulate growth in production

period, with reports covering the calendar year 1946, under an arrangement by which the Office of the Board of Engineers, War Department, has become the collecting and tabulating agency. For the first six months of 1946 the commodity classification will be the same as in the prewar reports; for the last six months the commodity breakdown will be in accordance with the old I.C.C. freight commodity statistics classification. Beginning with 1948 , the data will be classified in accordance with the revised I.C.C. commodity classification, effective January I, r947, thereby assuring a much needed uniformity in commodity detail between intercoastal water and rail traffic statistics.

${ }^{11}$ Statements numbered M-550 (SCS), now on a quarterly and calendar-year basis. Beginning January $\mathrm{I}, \mathrm{I947}$, these statements will be designated Q-250 (SCS), reflecting the new and refined commodity classification. 
and utilization of resources at such disadvantaged points and still yield the carriers adequate revenues. Ability to find other producing points from which traffic movements to the projected markets have occurred and to discover the freight-rate and mileage relationships between all such points and common markets, on the one hand, and the rates from the points where production is limited, on the other hand, would be an indispensable aid in discovering whether the transportation factor is responsible for retarded development.

Point-to-point traffic flows of individual commodities by type of rate, such as are needed for studies of the significance of freight-rate differences, and state-to-state traffic movements, such as would be useful in industrial location work by revealing interregional economic relations, could be assembled from waybills concurrently with data showing point-to-point rate and mileage relations on an individual commodity basis. The sampling method would give adequate results, and samples would not have to be taken frequently since basic traffic patterns, like industrial and marketing patterns, usually are subject to only gradual change. ${ }^{12}$

\section{Cost of Transportation Service}

Transportation cost-finding constitutes another area in which the available data have generally been inadequate for the variety of transportation analyses for which cost data are essential, including the question whether existing differences in territorial and interterritorial rate levels are justifiable under the Interstate Commerce Act. The needs that exist for more refined cost data have heretofore been neglected in this discussion not because the subject lacks importance but because relatively more progress has been made in cost-finding for regulatory purposes than in development of specific rate, mileage, and traffic flow data. ${ }^{13}$

Without having attained perfection in cost-finding, the Interstate Commerce Commission was able to conclude in its Class Rate Investigation decision that "there is no doubt that, based upon cost of service considerations, the differences in levels, schemes, and progressions of scales that at present occur in the several territorial class-rate structures here under review are not justified."14 Thus, although this finding was not unanimous, with respect to one fundamental part of the rate structure there appears strong evidence that a problem of discrimination not justified by cost differences exists, and the regulatory body is proceeding with corrective action. But the argument goes on as vigorously as ever whether the class-rate-level disparities are significant to the economic welfare of the rate territories principally concerned, because of lack of data of the types described above and of refined analyses of the

\footnotetext{
${ }^{12}$ See Bureau of Transport Economics and Statistics of the Interstate Commerce Commission, Regtonal Shifts in the Postwar Traffic of Class I Railways, Statement No. 4622, File 314-B-6, September, 1946, Vol. I, p. 6.

${ }^{13}$ For an excellent discussion of the usefulness and problems of cost-finding, see the statement by Dr. Ford K. Edwards, Cost Analysis in Transportation, read before the American Economic Association, Atlantic City, New Jersey, January 25, I947 (37 AM. Econ. Rev. Proc. 44I (1947)). See also 262 I.C.C. $447,571-591,692-927$ (1945).

14 262 I.C.C. 447,694 (1945). See Commissioner Porter's criticism of the majority's cost-finding in his dissenting opinion, id at 717-719, and H. R. Doc. No. 303, 78th Cong., Ist Sess. 25I-285 (1943).
} 
economic significance of class-rate-level differences with respect to particular industries aud enterprises.

For the purpose of checking the specific justification that might or might not exist in transportation conditions for material differences in particular rates, existing cost data and procedures are less adequate. Here, too, the age-old problem of whether and to what extent it is tenable to base individual rates on specific costs of service, with necessarily arbitrary allocations of overhead and joint costs, has to be faced, together with questions regarding the particular measures or levels of costs that may appropriately be referred to in testing the justification for rate differences. Notwithstanding this complexity, and without subscribing to a cost basis for particular rates, it may be observed that more adequate cost measures, like shortline distance data, would be a helpful aid in determining whether differences in particular sets of rates found to exist are justifiable. Irrespective of whether such differences have a marked influence upon economic development in territories with the higher rates, if they run foul of legal standards of rate control action should be taken to remove them.

\section{III}

\section{Development of More Adequate Transportation Data}

From this description of gaps in available transport statistics needed for evaluation of freight-rate discrimination and for a variety of other purposes, it is apparent that an urgent requirement for constructive action is that more adequate commoditymovement, rate, and mileage data be obtained. The possibilities of developing additional data of those types may now be sketched briefly.

With respect to the initial problem of ascertaining where freight-rate differences exist in the rate structure and their magnitude, it may be observed that available data and studies appear adequate for general agreement on the facts in regard to differences in territorial and interterritorial class-rate levels. ${ }^{15}$ The problem of unknowns arises rather in connection with exception rates, which are responsible for about II per cent of aggregate carload traffic, and commodity rates, on which approximately 85 per cent of the nation's carload traffic moves. ${ }^{16}$ Additional data showing the point-to-point rates and shortline mileages for these segments of the rate structure are urgently needed. As already indicated, point-to-point traffic flow data associated with specific rate and mileage data are needed for all types of traffic to reveal the importance of each type of rate to particular industries, to locate significant traffic movements, and to throw light upon the effect of rates upon traffic and industrial development. ${ }^{17}$

\footnotetext{
${ }^{18}$ Class Rate Investigation, 1939, 262 I.C.C. $447,566-569,744-765$ (I945); and H. R. Doc. No. 303 , cited supra, note 14 , at 20-2I, 55-56, 90-91, 150, and $165-175$.

${ }_{10} 262$ I.C.C. $447,548-550,564,570-57 x, 593-600,601-604$ (1945); H. R. Doc. No. 303, cited supra, note 14, at 92-148, I85-221; and Transportation Program for SMarl Bosiness, Report of thiE Transportation Subcomamttee to the Senate Spectal Committee to Study Problems of American Smazi Business, Pursuant to S. Res. 28, 79th Cong., 2d Sess. I6-i7 (I946).

${ }^{27}$ Transportation Program for Small Business, cited supta, note 16 , at 25-27, 3I-32.
} 


\section{BIR Waybill Sample of 1939 Railroad Traffic}

Fortunately, a source already has been developed which could provide much of the needed information with respect to rates, mileages, and specific traffic movements for the benchmark year, 1939. In connection with its studies of relative economy and fitness of carriers by highway, railroad, and water and its study of the interterritorial freight-rate problem, the Board of Investigation and Research, a temporary research agency established by the Transportation Act of 1940 , took a twelve-day waybill sample of 1939 rail carload traffic which, if tabulated on a point-to-point basis for individual commodities, would afford a comprehensive picture of the rate structure and an excellent basis for measurement of freight-rate differences applying to traffic actually moved in that year. ${ }^{18}$

A brief description of the characteristics of the BIR waybill sample and the specific types of data which are obtainable from or in conjunction with that source will facilitate consideration of steps that might be taken toward making essential data available. The sample totals 690,000 copies of waybills or waybill abstracts representing the movement of more than 900,000 carloads of I939 traffic, or all waybills of carload traffic terminated by class I railroads during one day each month of that year. Different days of the month were assigned to the railroads in each region to obtain traffic representative of seasonal movements. The tonnage reported amounted to 3.9 per cent of the total 939 carload tonnage reported by all class I railroads to the Interstate Commerce Commission. Although the sample is more representative of aggregate carload traffic and of traffic by commodity groups than it is of movements of individual commodities between particular origins and destinations or states, the question of representativeness is not of such critical importance when the data are used for the purpose of determining point-to-point rate and mileage relations as it is when they are used for other purposes. ${ }^{10}$

Each of the copies of waybills or waybill abstracts which were prepared by the terminating railroads shows the following details:

Date of waybill

Originating railroad, station, state, and rate territory

Terminating railroad, station, state, and rate territory

Route of movement, including junctions and carriers on interline traffic

Commodity name and ICC group number

${ }^{18}$ For a complete description of this waybill sample, see Excerpts from the Board's Reports Concerning Its Carload Traffic Study, 1939, a mimeographed release of the BIR, now available in the Interstate Commerce Commission, to which agency the study files of the BIR were transferred after the latter agency ceased operations on September 18, 1944. Some of the preliminary statistical results of this survey are shown in the Board's study, The Natronal Traffic Pattern, S. Doc. No. 83, 79th Cong., Ist Sess. 28-56 (1945).

${ }^{10}$ For observations on the representativeness of the BIR waybill sample, see BonRd of INVEstroation and Research, Preliminary Report on the Relattve Economy and Fitness of the Carriers, H. R. Doc. No. 595, 78th Cong.. 2d. Sess. 15 (1944); Excerpts from the Board's Reports Concerning Its Garload Traffic Study, 1939, cited supra, note 18; The Natronal Traffic PatTERN, cited supra, note 18, at 9-ir; and Regional, Shifts in the Postwar Traffic of Class I Railways, cited supra, note 12 , Vol. I, 138, Vol. II, 299-300. 
Weight of the shipment

Rate assessed

Freight charges, including advances but excluding charges for miscellaneous services

Where applicable, whether joint shipment (if joint rail-water or rail-highway), reconsigned (if reconsigned enroute), and transited (if under transit privilege)

Route mileage over which the car moved origin to destination

Date terminated

Number of carloads.

It will be noted that the waybill abstracts assembled by the BIR do not reveal the type of rate on which each shipment moved, the first-class rate, nor the shortline mileage-all essential items for effective analysis of the significance of freight-rate differences. In order to associate specific commodity movements with class, exception, or commodity rates and with shortline or rate-making distances, it is necessary to obtain these items from classifications, tariffs, and mileage books and to insert them on the copies of waybills or waybill abstracts prior to tabulation on a point-to-point basis. In practice, these operations can be conducted when the rates and charges shown upon the waybills or waybill abstracts are being verified, but they involve extremely time-consuming procedures which make tabulation on a point-to-point basis an expensive procedure. ${ }^{20}$

Before its statutory life ended the BIR made a number of compilations on the basis of the twelve-day waybill sample data, including a tabulation showing for each of ${ }^{5} 6$ carload commodity groups the movements originating in each state by state of termination and those terminating in each state by state of origin. ${ }^{21}$ These stateto-state movements, although not broken down by individual commodities, are of greater value for general analyses of interregional trade and economic relationships and for locating possible industrial opportunities than they are for tracing the economic effects from freight-rate disparities. As already indicated, point-to-point breakdowns showing rate, mileage, and rraffic relations for individual commodities are necessary for the latter purpose.

The BIR undertook special studies of lime, potatoes, and paperboard products for which it assembled the first-class rate, type of rate, and shortline distance data and tabulated these and the other waybill data on a point-to-point basis by a handtabulating procedure that proved to be an efficient method of obtaining a list of point-to-point shipments arranged by ascending shortline distances by type of rate and territorial movement. ${ }^{22}$ For each point-to-point shipment arrayed in this manner the following data were provided:

\footnotetext{
${ }^{30}$ Bureau of Transport Economics and Statistics, Interstate Commerce Comaission, The Transportation of Fresh Apples, Statement No. 468, File No. 40-C-2, I-4.

${ }^{21}$ These compilations and studies based upon them are described in $i d$. at 2-3. On page 3 it is stated: "These compilations are available in unpublished form in the files of the House Committee on Interstate and Foreign Commerce, the Senate Committee on Interstate Commerce, and the Bureau of Transport Economics and Statistics of the Interstate Commerce Commission."

${ }^{22}$ Some of the results of these exploratory studies were not published, but the data obtained on circuity of movement and cross-hauling appear in The Nattonal Traffic Pattern, S. Doc. No. 83,79 th Cong., Ist Sess. 47-57 (1945).
} 
The serial number of the waybill

Originating railroad, station and state

Terminating railroad, station and state

Actual and shortline miles

The first-class rate and the percentage relation of the effective rate to the first-class rate By type of rate on which the shipment moved, the number of cars, the weight of the shipment, the actual rate, and the charges assessed

Information as to whether the rate was a joint rate or involved reconsignment or transit privileges.

The completion of point-to-point tabulations such as were started by the BIR would have provided a detailed view of the railroad rate structure and rate differences that is now not available. In addition to revealing a variety of rate disparities in terms of the shortline mileage standard between territories, within territories, and even within single states, these trial tabulations have demonstrated the feasibility of using waybill samples to obtain specific rate and commodity-movement data of the type that has long been needed for a variety of transportation and industrial research purposes, including evaluation of interterritorial rate disparities. As a result, the interest of a number of Government agencies and many state and private research groups, including individual business firms, in continuing sample waybill studies has been awakened, and the Interstate Commerce Commission, the public repository of the BIR files, is making a limited number of point-to-point tabulations on the basis of the twelve-day I939 sample, and has inaugurated a continuous sample of carload traffic approximating one per cent of total carload traffic. ${ }^{23}$ Although the adequacy of that sample for various purposes will have to be explored by analysis of the results, and no announcements have been made to indicate the specific data breakdowns which the Commission will ultimately release, it is apparent that much of the data needed for further and more refined analysis of the economic significance of interterritorial freight rates could be obtained from this additional waybill source.

It is therefore clear that progress is being made toward filling in some of the gaps in available statistical equipment for specific analyses of the significance of freight rates and other transportation factors to location of industry and development of markets. It should be observed, however, that new and continuing waybill samples do not obviate the need for completion of the BIR sample of I939 carload traffic, because that year is a basic benchmark year previous to the vast industrial changes of the World War II period. While there have been both general rate advances and changes in traffic since I939, adjustments can easily be made for changes in rates, and it is usually well known where industrialization has occurred that would sharply affect a territorial breakdown of traffic. Another reason is that specific

\footnotetext{
${ }^{23}$ See the Commission's order of September 6, 1946. Effective November 1, 1946, and thereafter unless ordered otherwise, Class I railroads are directed "to file an authentic copy of the front only of the audited waybills for all carload shipments terminated, whose waybill serial numbers are ' 1 ' or cnd with 'or." The sampling procedure takes a straight one per cent sample of the larger stations having more than roo waybills per month, based on the numbering system utilized by the stations themselves. The smaller stations are classified in accordance with the expected number of waybills for the month and sampled on the basis of probabilities within the classification.
} 
point-to-point data are needed immediately and data can be obtained from the BIR waybill sample more quickly than from other sources. ${ }^{24}$

\section{Census Procedures}

An important development toward obtaining more adequate transportation data in relation to industry is the interest currently being shown in bills to authorize the Bureau of the Census to include questions on transportation, exclusive of railroads and other modes where existing data may be adequate, in the censuses of manufactures, mineral industries, and other businesses, to be taken every five years, beginning in $194^{8}$. If legislation of this kind is enacted and if questions are included in the manufacturing and other schedules to ascertain the tonnage into and out of individual plants and business locations by mode of transport and the payments for transportation service, data will become available which will enable analysts to determine the significance of each mode of transportation to individual industries and the importance of transportation cost as a production and marketing factor. ${ }^{25}$ Railroad freightrate differences that are sufficient to be burdensome would have that effect only to the extent that the traffic of a firm or an industry could not be diverted to a more economical agency. Data showing the division of traffic in particular industrial situations, such as could be obtained by census procedures, would throw much light upon the extent to which producers in territories having higher railroad rates have been able to shift to other forms of transportation.

\section{Case Studies of Significance of Transportation Factors}

Adequate transportation data alone will not suffice to isolate the economic effects of territorial freight-rate differences. As indicated above, when sufficient specific rate, mileage, and commodity-movement data are at hand to locate areas where significant freight-rate differences may exist, knowledge of the problems requiring study and attention will become more definite. A basis will then be available for further examination of the particular situations in which the effects of freight-rate differences might be considerable. To discover whether they are, however, will require detailed studies of all of the production and marketing factors influencing the profit opportunities of particular firms and industries in the higher-rated territories as compared with those in the lower-rated territories. These case studies should be historical in approach so as to reveal the long-term significance of each locational factor in the

24 The I.C.C.'s Bureau of Transport Economics and Statistics is in the process of making point-to-point tabulations from the BIR sample, showing for each commodity group (sometimes for each product in the group) the origin city and state, the destination city and state, the month in 1939 of the shipment, the actual and shortline miles, the first-class rate, the actual rate per cwt., the weight of the shipment, and the total freight charges, for three groups of commodities comprising 37 agricultural and industrial commodity classes and $83,36 \mathrm{r}$ carloads. Two such tabulations, covering Commodity No. 550, common brick, and Commodity No. I10, oranges and grapefruit, have been completed and made available to interested government agencies. It is understood, however, that the data from such tabulations can be released to the public only in such manner as not to reveal the traffic of individual firms.

${ }_{2 \pi}$ The Senate Civil Service Committee on April 24, r947, reported favorably on S. 554, which would authorize the Bureau of the Census to take transportation censuses along with censuses of manufactures and other businesses. Sen. Rep. No. 141, 80th Cong., ist Sess. (1947). On May 6, the Senate passed this bill. 93 Cong. Rec. $4692-4693$ (I947). 
past development of each territory as a preliminary to evaluation of future possibilities. The possession of point-to-point rate and shortline mileage relations, together with relative traffic volumes, would contribute markedly to appraisal of the influence of transportation factors upon future development.

Meanwhile, the issues with respect to interterritorial freight rates must be settled on the basis of the best judgment possible in view of existing gaps in necessary information. Since resolving these issues will undoubtedly require a long time, there will be ample opportunity for research groups and students to make more specific analyses of the effects of freight-rate disparities than have been available in the past. The progress that is being made toward obtaining more adequate transportation data, although slow, offers encouragement to those who would attempt the muchneeded case studies of industrial location. 